\title{
A experiência de um serviço de saúde especializado no atendimento a pacientes indígenas
}

\section{The experience of a specialized health service for the care of Indian patients}

\author{
Érica Ribeiro Pereira \\ Doutora em Ciências pela Universidade Federal de São Paulo. \\ Enfermeira do Ambulatório do Índio. Servidora Técnica Adminis- \\ trativa em Educação na Universidade Federal de São Paulo. Aluna \\ do curso de especialização em Inovação e Gestão em EAD pela USP. \\ Endereço: Rua Engenheiro Jorge Oliva, 237, apto I82a, CEP 04362- \\ 060, São Paulo, SP, Brasil. \\ E-mail: erica.ribeiro®unifesp.br

\section{Elisabeth Peres Biruel} \\ Mestre em Educação em Saúde pela Universidade Federal de São \\ Paulo. Bibliotecária plena do Centro Latino Americano e do Caribe \\ de Informação em Ciências da Saúde. \\ Endereço: Rua Botucatu, 862, Vila Clementino, CEP 04023-090, \\ São Paulo, SP, Brasil. \\ E-mail: elisabeth.biruelळbireme.org

\section{Lavínia Santos de Souza Oliveira} \\ Doutora em Saúde Pública pela Universidade de São Paulo. Enfer- \\ meira, Coordenadora de Recursos Humanos do Projeto Xingu do \\ Departamento de Medicina Preventiva da Universidade Federal \\ de São Paulo. \\ Endereço: Rua Estado de Israel, 113 , Vila Clementino, CEP 04022- \\ ०oo, São Paulo, SP, Brasil. \\ E-mail: laviniasoliveiraळgmail.com

\section{Douglas Antônio Rodrigues} \\ Doutor em Saúde Coletiva pela Universidade Federal de São Pau- \\ lo. Médico, coordenador da Unidade de Saúde e Meio Ambiente \\ do Departamento de Medicina Preventiva da Escola Paulista de \\ Medicina, Universidade Federal de São Paulo. \\ Endereço: Rua Estado de Israel, 113 , Vila Clementino, CEP 04022- \\ ○०o, São Paulo, SP, Brasil. \\ E-mail: douglas.rodriguesळunifesp.br
}

\section{Resumo}

Estudo descritivo, de natureza qualitativa, na modalidade de relato de experiência. Trabalho desenvolvido em serviço de saúde especializado no atendimento a pacientes indígenas a partir de atividades de extensão universitária em acolhimento, promoção e educação em saúde. O Ambulatório do Índio e Hospital São Paulo da UNIFESP são referências no atendimento de média e alta complexidade aos povos indígenas de diversas regiões do Brasil. Os projetos de extensão tiveram por finalidade criar espaços de conversa, identificar percepções sobre processo saúde-doença e estabelecer projeto de cuidado a partir da identificação das necessidades do paciente indígena. Desafiou a equipe de saúde a proposta de formar vínculo com pacientes indígenas que ultrapasse o objetivo de resolução de um problema de saúde, mas adentre nas interfaces entre saúde, cultura e modo de vida. Conclui-se que o Ambulatório do Índio é um espaço permanente de reflexão para o atendimento diferenciado ao paciente indígena nos campos da assistência, ensino, pesquisa e extensão. Palavras-chave: Saúde de Populações Indígenas; Serviços de Saúde do Indígena; Promoção da Saúde; Educação em Saúde; Acolhimento. 


\section{Abstract}

A descriptive study, of qualitative nature, in the modality of experience report. A paper developed in a specialized health service for the care of Indian patients, based on university extension activities of users' reception, health promotion and education. The Indian outpatients clinic and São Paulo's Hospital, of the Federal University of São Paulo, are references in medium and high complexity service to Indian populations in several regions in Brazil. The extension projects were intended to create conversation spaces, to identify perceptions about the health-disease process and to establish a health care project, from the identification of the indigenous patient needs. The proposal of forming bonds with Indian patients that go beyond the objective of solving a health problem to enter the interfaces among health, culture and life style was a challenge for the health staff. It can be concluded that the outpatient clinic of the Indian is a permanent space for reflection, for a differentiated service to these patients in the areas of health assistance, teaching, research and extension.

Keywords: Health of Indian People; Indian Health Services; Health Promotion; Health Education; User Reception.

\section{Introdução}

A população indígena no Brasil, segundo o censo do Instituto Brasileiro de Geografia e Estatística (IBGE) 2010 é de 817.963 pessoas, o que representa o,42\% da população do País pertencentes a 305 etnias e falantes de 274 línguas. Destas, 315.18o vivem nas cidades e $502.783 \mathrm{em}$ aldeias (ISA, 2012). Em um passado recente, as condições de saúde da população indígena eram marcadas predominantemente pela presença das doenças infecciosas e parasitárias. Epidemias de viroses como gripe e sarampo dizimavam milhares de indivíduos em curto intervalo de tempo (Santos e Coimbra Jr., 2003).

Para atender as especificidades culturais, epidemiológicas e geográficas desses povos foi instituído pela Lei 9.836 de 1999 um modelo complementar e diferenciado de organização dos serviços de atenção básica, o Subsistema de Atenção à Saúde Indígena (SASI) componente do Sistema Único de Saúde (Brasil, 2002a, 2012). Nesse subsistema, a maioria dos agravos à saúde indígena deverá ser resolvida na atenção básica. Os casos mais complexos são referenciados para a rede de serviços de média e alta complexidade do SUS. Para dar suporte a esses pacientes e acompanhantes, foram criadas as Casas de Apoio à Saúde Indígena (CASAIs) que têm por função alojar e prestar assistência de enfermagem 24 horas por dia. Na maioria das vezes, as CASAIs estão localizadas em municípios próximos aos territórios indígenas ou em grandes centros que dispõem de serviços de saúde especializados.

Os povos indígenas vêm experimentando mudanças no estilo de vida que tem repercutido na emergência das doenças crônicas não transmissíveis, a destacar: dislipidemias, diabetes melito, hipertensão arterial, doenças cardiovasculares, neoplasias, doenças psiquiátricas e alcoolismo (Santos e Coimbra Jr., 2003; Gimeno e col., 2007; Salvo e col., 2009). A procura por serviços de saúde especializados tende a aumentar com a crescente mudança no perfil epidemiológico desses povos.

É função da atenção primária à saúde desencadear intervenções nas comunidades indígenas com vista à promoção da saúde e prevenção de doenças que poderão colaborar para melhoria das condições de vida dessa população. Ao mesmo tempo, é fun- 
damental que os serviços de saúde de média e alta complexidade conheçam os aspectos socioculturais que interferem nos processos de saúde-doença dos diferentes povos indígenas para acolher e intervir segundo suas necessidades, propondo projetos de cuidado mais efetivos e condizentes com o entendimento e a realidade de cada grupo populacional.

Partindo deste cenário, este trabalho se propõe a descrever a experiência de um serviço de saúde especializado no atendimento a pacientes indígenas e refletir criticamente sobre iniciativas de projetos de extensão universitária em acolhimento, promoção e educação em saúde indígena.

\section{Método}

Este estudo consiste em relato de experiência vivenciado pela equipe multiprofissional de um ambulatório especializado no atendimento a saúde indígena da Universidade Federal de São Paulo (UNIFESP), no período compreendido entre 2008 a 2012. A descrição orienta-se por abordagem qualitativa com observação direta dos autores e equipe multiprofissional do serviço. Como forma de acessar as informações que subsidiassem o estudo, optou-se pela análise documental utilizando-se de relatórios, atas, planilhas e outros documentos produzidos e compilados pela equipe no decorrer do período de 2008 a 2012.

A proposta é descrever alguns aspectos sobre a importância, características e funcionamento desse ambulatório que é singular no atendimento à saúde indígena no Brasil. Além das atividades assistenciais, daremos ênfase à participação de alunos de graduação em medicina e enfermagem da universidade em projetos de extensão universitária voltados para o acolhimento, promoção e prevenção à saúde de pacientes indígenas. Este estudo trará contribuição em dois aspectos: as particularidades de um serviço de saúde especializado que atende pacientes indígenas e a participação de alunos de graduação em projetos de extensão universitária em saúde indígena.

Os temas dos projetos de extensão foram concebidos mediante a necessidade do serviço e contemplaram aspectos de iniciação científica. Os alunos de graduação eram incentivados a refletir sobre a realidade observada, interagir com a clientela indígena e buscar referências teóricas para análise e redação de relatório científico individual no fim do período estipulado. Cada aluno permanecia no projeto por um período de um ano.

No tocante aos projetos, as seguintes atividades foram desenvolvidas ao longo de cada período:

- Encontros semanais entre os profissionais do ambulatório e alunos para orientação;

- Encontros de supervisão mensais com a orientadora para avaliação;

- Aproximações com a realidade indígena mediante leituras, discussão de textos, visitas à CASAI São Paulo (SP), Projeto Xingu e acompanhamento de pacientes e familiares ao Hospital São Paulo (HSP);

- Realização de entrevistas com os pacientes atendidos no Ambulatório do Índio;

- Elaboração de um relatório técnico ao final de período de um ano.

Os resultados das entrevistas e observações realizadas pelos alunos e profissionais foram analisados mediante a metodologia de análise documental e sistematização de experiências. O referencial teórico utilizado foi dos campos da saúde coletiva, saúde indígena e antropologia.

\section{Atendimento especializado em saúde indígena}

A Escola Paulista de Medicina (EPM) da UNIFESP acumula considerável experiência no atendimento à saúde dos povos indígenas por meio do programa de extensão conhecido como Projeto Xingu. Desde 1965 desenvolve atividades de assistência, pesquisa, extensão e formação de recursos humanos no Parque Indígena do Xingu, Mato Grosso, e também junto a outros grupos indígenas e comunidades ribeirinhas (Baruzzi, 2007).

O Hospital São Paulo (HSP), hospital universitário da EPM, é referência no atendimento a diferentes povos indígenas de diversas regiões do Brasil por ser um serviço que agrega recursos tecnológicos e profissionais especializados.

Para contribuir de forma efetiva na atenção à saúde de média e alta complexidade do País e melhorar o acolhimento da população indígena foi criado, em 1989, o Ambulatório do Índio/HSP ligado 
à Unidade de Saúde e Meio Ambiente do Departamento de Medicina Preventiva/EPM. Sua missão é fazer acolhimento, coordenação dos cuidados e acompanhar o itinerário diagnóstico e terapêutico do paciente indígena, ou seja, os caminhos percorridos nas diferentes especialidades do HSP e outros serviços por meio de equipe de referência (figura 1 ). Entende-se como equipe de referência um grupo de profissionais de diferentes áreas e saberes, organizados em função dos objetivos de um serviço de saúde, sendo percebidos como referência para os usuários desse serviço (Brasil, 2008). Cabe ainda, a construção da rede de cuidados nos diversos espaços por onde transita esse paciente repleto de ansiedades, dúvidas e questionamentos.

Os pacientes indígenas encaminhados ao Ambulatório do Índio são oriundos, na sua maioria, das regiões norte e centro-oeste do País, apresentando como principais patologias: neoplasias, malformações congênitas e cardiopatias (UNIFESP, 2008). 0 tempo de permanência desses pacientes em tratamento tende a ser prolongado, em média de três a quatro meses, em decorrência da complexidade das patologias, dos casos que necessitam de cirurgias e da dificuldade de deslocamento devido à distância da região de origem. 0 tempo prolongado que os pacientes permanecem hospedados na CASAI SP, associado à ociosidade, é um gerador de ansiedade que, em alguns casos, culmina na vontade de desistir do tratamento e retornar para a aldeia e até conflitos interétnicos. Além disso, existe a preocupação e saudades da família que foi deixada na aldeia. Todos estes elementos são levados em consideração pela equipe do Ambulatório do Índio e CASAI SP que se dispõem a ouvir, orientar e negociar com o próprio paciente, durante todo o tempo, a melhor forma de resolvê-las. A grande diversidade sociocultural dos pacientes indígenas e o despreparo dos serviços de saúde em lidar com essas diferenças é um desafio para a média e alta complexidade no atendimento diferenciado e singular. Entende-se como atendimento diferenciado o modelo de assistência em que as ações de saúde devem ser adaptadas às peculiaridades socioculturais, epidemiológicas e demográficas das diversas etnias indígenas. A atenção diferenciada não significa simplesmente a incorporação das práticas tradicionais desses povos, mas da articulação das práticas de autocuidado com os serviços de saúde (Menéndez, 2003; Silveira, 2004).

o Ambulatório do Índio conta com equipe multiprofissional composta por médicos, enfermeiros, técnico de enfermagem, nutricionista e recepcionista que possuem experiência prévia em saúde indígena com vivências em algumas comunidades. A maior proximidade dos profissionais com as questões culturais indígenas minimiza o estranhamento imediato, principalmente em um ambiente urbano e hospitalar, facilitando o diálogo, mas pode não ser suficiente para abarcar as dimensões socioculturais que emergem dos povos indígenas cujas realidades são diversas e requer um olhar singular e diferenciado. Para os profissionais que atuam na saúde indígena, a disponibilidade em ouvir, ao diálogo é uma das habilidades mais importantes a ser construídas e exercitadas (Mendonça, 2010).

$\mathrm{O}$ atendimento no Ambulatório do Índio se dá a partir da demanda referenciada das CASAIs regionais para a CASAI localizada na cidade de São Paulo que possui 40 leitos para acomodar pacientes e acompanhantes. Existe demanda reprimida principalmente das regiões norte e centro oeste do País. Isto se deve à restrição de leitos na CASAI SP associada à pouca rotatividade dos pacientes que necessitam permanecer maior tempo até o término do tratamento. As vagas são cedidas pela CASAI SP após discussão com equipe multiprofissional do ambulatório, priorizando casos de maior gravidade.

Nesse ambulatório, os pacientes recebem o primeiro atendimento e, quando necessário, são encaminhados para serviços especializados do HSP. Os acompanhantes que apresentam alguma queixa também são atendidos nesse serviço. No decorrer da investigação, os pacientes são acompanhados pela equipe de referência, retornando quantas vezes forem necessárias para consultas médicas e conversas com a equipe relacionadas ao tratamento e dúvidas dos pacientes. Após o término do período de investigação e tratamento, esse paciente retorna ao Ambulatório do Índio para receber alta. A equipe do ambulatório, a partir das informações e procedimentos realizados nas diferentes especialidades do HSP, faz o relatório de alta e as recomendações de seguimento para a CASAI SP que remete à CASAI de origem. Além dos pacientes da CASAI SP, o ambulatório atende indígenas residentes na capital, no litoral e na Grande São Paulo que chegam por 
demanda espontânea ou são encaminhados por outros serviços de saúde.

A responsabilização da equipe de referência pelo paciente indígena perpassa o atendimento à saúde. Reuniões com proposta de proporcionar melhor resolutividade e atendimento a esse paciente com consequente redução no tempo de permanência em São Paulo são realizadas periodicamente. Nessas conversas são valorizados outros aspectos, além daqueles voltados para o diagnóstico e terapêutica. Discutem-se problemas de ordem emocional, familiar, de adaptação que repercutem em seu tratamento. As reuniões acontecem entre a própria equipe de referência, com a equipe da CASAI SP e equipes das especialidades do HSP, quando necessário. Esta interação é fundamental para a construção da rede de cuidados entre os serviços e pacientes. Também é um espaço para construção do projeto terapêutico singular, uma reunião com conjunto de propostas e condutas terapêuticas articuladas para um sujeito, resultado de discussões em que todas as opiniões são importantes para ajudar a entender o sujeito e sua demanda de cuidado de saúde (Brasil, 2007).

Outro espaço de interlocução importante para a equipe de referência é o indígena hospitalizado. $\mathrm{O}$ contato com a equipe multiprofissional do HSP pode minimizar o impacto das diferenças culturais, propiciando espaço de diálogo com enfoque cultural em situações como: dificuldade de entendimento entre a equipe e o paciente que não compreende os procedimentos e por sua vez não colabora com o tratamento, casos que necessitam negociar alta hospitalar, discutir procedimentos cirúrgicos com o paciente, trazer um pajé para dentro do hospital, acesso de acompanhante e tradutor junto ao paciente e adequação da dieta hospitalar. No campo da saúde, a relação intercultural, entendida como o relacionamento, a convivência com outras culturas, demanda um olhar que transcende a relação profissional-paciente e se estende ao contexto sociocultural com reflexão sobre as diferentes concepções de corpo, de pessoas, de adoecimento e tratamento. Mendonça (2010) nos diz que

à medida que nos distanciamos de nossa sociedade e conhecemos outras formas de ver, de ser e estar no mundo, somos levados a refletir sobre nossa própria cultura, nossas regras sociais que foram sendo construídas ao longo de nossa história, a partir dos encontros e desencontros de várias culturas. Conhecer o diferente passa por uma reflexão sobre a nossa prática, confirma a necessidade de se dispor a ouvir, se dispor ao diálogo. Essa é uma das habilidades mais importantes que os profissionais de saúde que atuam em saúde indígena devem exercitar e construir (p. 185-188).

No ambiente hospitalar têm emergido novas concepções de gestão da saúde que sejam capazes de produzir mudanças nos sujeitos e nas práticas de cuidado. A introdução de mudanças na arquitetura dos serviços de saúde e a reorganização dos processos de trabalho têm sido inovações em toda a rede do SUS. Como princípios e diretrizes para uma gestão inovadora dos hospitais, destacam-se:

(1) Tomar o adoecimento humano como fenômeno complexo, o que exige ação articulada e integrada entre múltiplos territórios de saberes e práticas; (2) Acolher a diversidade, a pluralidade e a multiplicidade social e subjetiva dos sujeitos para a composição de projetos terapêuticos; (3) Compreender que a produção de saúde se afirma como um projeto de produção e ampliação da autonomia com o outro: usuário, família, comunidade; (4) Compreender que o cuidado em saúde é sempre singular e sua capacidade de produzir e qualificar a vida decorre da qualidade dos encontros entre os sujeitos (Brasil, 2011, p. 38).

A partir da necessidade de os serviços e profissionais de saúde apropriarem-se de um olhar multicultural e sensível, foi proposto por Campinha-Bacote (1995, 2002) um modelo de cuidado culturalmente competente. A competência cultural como definido por essa autora é um conjunto de comportamentos, atitudes e políticas que permite ao prestador de cuidado agir de forma eficiente em situações transculturais. Sendo um processo contínuo, envolve quatro componentes: a consciência, o conhecimento, a habilidade e o encontro cultural.

A diferenciação do atendimento no Ambulatório do Índio caracteriza-se por uma abordagem que valoriza os aspectos culturais envolvidos na determinação do processo saúde-doença, visando minimizar os conflitos entre o saber biomédico e o tradicional indígena. 


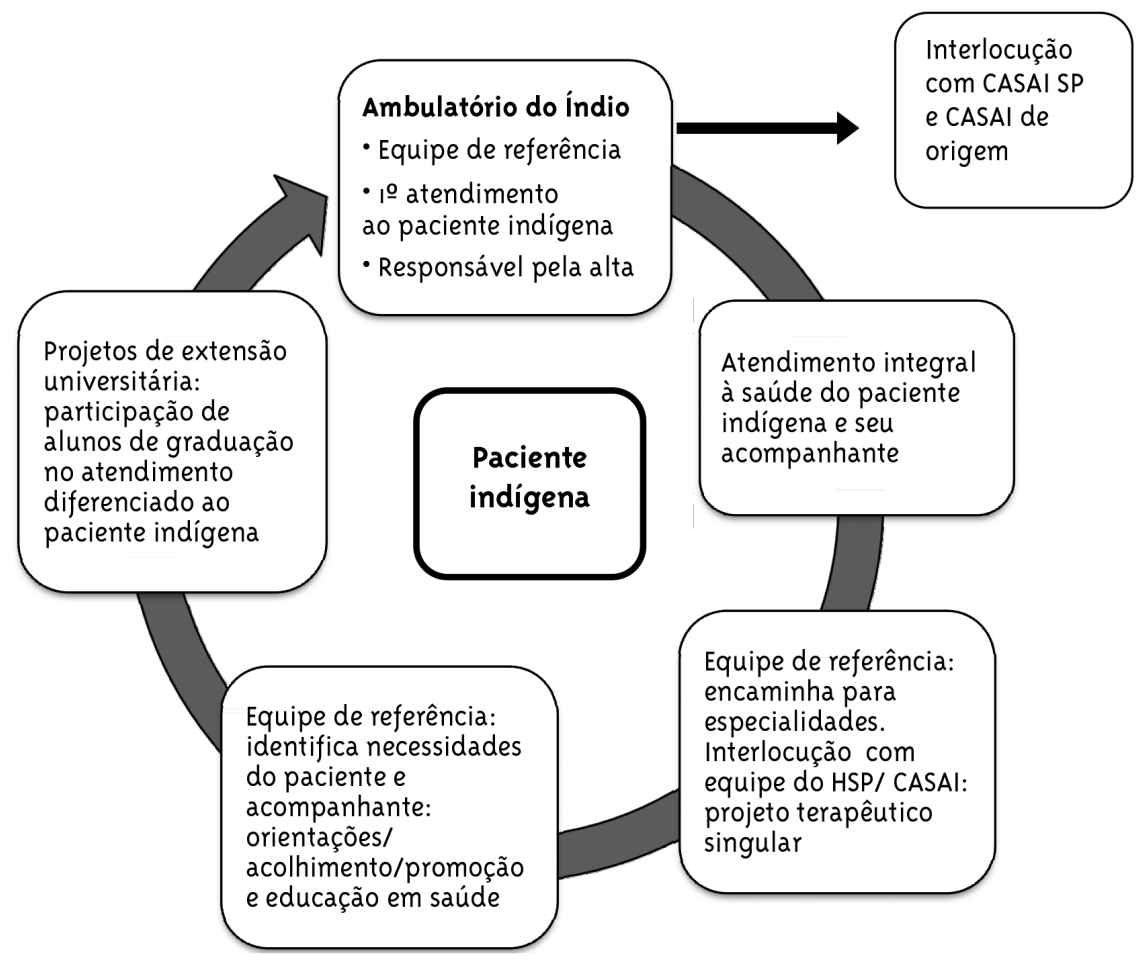

\section{Iniciativas de projetos de extensão universitária}

A universidade possui um papel social importante na sociedade e se alicerça no tripé assistência, pesquisa e extensão. 0 conceito de extensão é definido como um "processo educativo, cultural e científico que articula o Ensino e a Pesquisa de forma indissociável e viabiliza a relação transformadora entre Universidade e Sociedade" (Brasil, 2001). Nesse cenário, é fundamental a aproximação, a troca de conhecimentos e experiências entre docentes, discentes e população com possibilidade de desenvolvimento de processos de ensino-aprendizagem a partir de práticas cotidianas de ensino/pesquisa que possam confrontar teoria com o mundo real de necessidades e desejos (Hennington, 2005).

O Ambulatório do Índio prioriza a participação de alunos de graduação em suas atividades de assistência à saúde indígena cujo propósito é inserir, durante a graduação, vivências que sensibilizem e aproximem os alunos da realidade da saúde indíge- na no País. A formação profissional, a educação em saúde, a pesquisa e extensão são eixos temáticos que dialogam com esse universo multifacetado, plural, que abriga espaços de ensinar e aprender.

Desde 2008, o Ambulatório do Índio desenvolve projetos de extensão universitária em acolhimento, promoção e educação em saúde indígena. Nesse período, participaram duas alunas de graduação em medicina e cinco em enfermagem. A proposta era despertar interesse em conhecer o universo cultural indígena como contribuição para sua formação acadêmica. Outro enfoque dessa atividade de extensão foi a iniciação à pesquisa com produção de relatórios e participação em congressos de extensão universitária. Os dois projetos foram aprovados pelo comitê de ética em pesquisa da UNIFESP e pela Comissão Nacional de Ética em Pesquisa (CONEP).

A coordenação e execução desses projetos foram realizadas por enfermeiras com experiência em saúde indígena. O enfermeiro vem conquistando um espaço importante como educador no âmbito da saúde indígena. A comunicação entre esse profis- 
sional e o paciente indígena vem se estabelecendo a partir de uma postura de negociação que implica troca mútua, de decisão participativa, valorizando a autonomia do sujeito.

\section{Projeto de extensão: acolhimento}

O acolhimento, uma das diretrizes de maior relevância ética, estética e política, é parte da Política Nacional de Humanização (PNH), criada em 2003, que se traduz em atitude favorável e sensível à escuta (Brasil, 2010).

Escutar significa a disponibilidade permanente por parte do sujeito que escuta para a abertura à fala do outro, ao gesto do outro, às diferenças do outro [...] é escutando bem que me preparo para melhor me colocar, ou melhor, me situar do ponto de vista das ideias. Como sujeito que se dá ao discurso do outro, sem preconceitos, o bom escutador fala e diz sua posição com desenvoltura (Freire, 1996, p. 75).

$\mathrm{O}$ ato ou efeito de acolher anuncia uma ação de aproximação, estar com, uma atitude de inclusão (Brasil, 2010).

Completando quinze anos desde a implantação do subsistema de saúde indígena, são incipientes as reflexões sobre o processo de acolhimento dessa população, principalmente nos serviços de saúde de média e alta complexidade. São nesses espaços que os pacientes indígenas encontram-se mais fragilizados e apresentam dificuldades de adaptação quando necessitam permanecer período prolongado de tempo distantes da família.

$\mathrm{O}$ acolhimento na saúde indígena é fundamental para formação de vínculo entre profissionais e pacientes. Uma forma de aproximar diferentes olhares, podendo facilitar a percepção das reais necessidades desse paciente. É nesse movimento de aproximação e estranhamento que opera o encontro com o outro, por meio do olhar e escuta sensível. Uma atitude acolhedora é uma atitude atenta e porosa à diversidade cultural, racial e étnica (Brasil, 2010).

Como prática de produção e promoção de saúde, o acolhimento implica a responsabilização do trabalhador/equipe pelo usuário, desde a sua chegada até a sua saída. Ouvindo sua queixa, considerando suas preocupações e angústias, fazendo uso de uma escuta qualificada, garantindo atenção integral, resolutiva e responsável (Brasil, 2008; Cavalcanti Filho e col., 2009).

Com o intuito de organizar e sistematizar o acolhimento no Ambulatório do Índio, foi produzido com a participação dos alunos de graduação, um roteiro de entrevistas semiestruturado levando em consideração aspectos importantes referentes à cultura indígena. Para subsidiar a estruturação do roteiro, foram realizados encontros, discussões de textos e visitas à CASAI SP. As conversas foram realizadas pela enfermeira do setor, envolvendo alunos de graduação em medicina e enfermagem da UNIFESP e pacientes indígenas provenientes da CASAI SP. Os espaços de conversa oportunizados pela equipe multiprofissional tiveram por finalidade criar vínculo, estabelecer confiança, conhecer o itinerário percorrido nos serviços de saúde, conhecer aspectos socioculturais, percepções e crenças sobre processo saúde-doença e identificar demandas dos pacientes e acompanhantes. Além disso, facilitar o entendimento do papel do Ambulatório do Índio, apresentar a equipe, a rotina do serviço e os diferentes lugares pelos quais iriam transitar durante o período de tratamento. Outro aspecto importante nas conversas foi a expectativa de tempo do paciente indígena e seu acompanhante em São Paulo e prepará-los para uma permanência prolongada a depender da complexidade do diagnóstico e tratamento. 0 projeto de cuidado é então estabelecido a partir da identificação das necessidades do paciente e acompanhante. Para Coelho e Jorge (2009), o acolhimento com diálogo possibilita à equipe multiprofissional ouvir e discutir as reais necessidades do usuário não apenas nos aspectos da sua doença, mas todo o contexto pessoal, social, econômico e cultural, buscando a melhor forma de resolvê-las.

Nesses espaços de conversa, encontramos indígenas que estavam em São Paulo pela primeira vez e desconheciam o que iriam enfrentar; ao lado de outros que já conheciam a lógica do serviço por terem retornado diversas vezes para seguimento do tratamento. Foi importante identificar que grande parte desses pacientes havia passado por diversos serviços em busca de solucionar um problema de saúde, trazendo histórias que remetem às dificuldades no acesso aos serviços de saúde e sua pouca resolutividade. 
Em busca de cuidados terapêuticos, o itinerário percorrido pelo paciente indígena inicia-se, frequentemente, pelas práticas da medicina tradicional indígena. Interessante destacar que, apesar de estarem recebendo tratamento em um serviço especializado, não houve distanciamento dos recursos da sua medicina. 0 uso de ervas, rezas e até a convocação de curadores tradicionais como pajés, rezadores e raizeiros é utilizado de forma concomitante ao tratamento biomédico. É comum o indígena vir para a CASAI trazendo consigo raízes para serem utilizadas na forma de chá, banho e massagem.

Os indígenas, bem como outros segmentos da população, utilizam-se de variados sistemas alternativos de saúde disponíveis, seja os tradicionais da cultura, seja os biomédicos, desde que apresentem comprovada eficácia, que torna o itinerário terapêutico bastante complexo e diversificado. A existência de diversos sistemas terapêuticos que envolvem o paciente gera a necessidade de os profissionais de saúde conhecerem a organização e redes sociais que sustentam as formas de autocuidado praticadas pelo paciente nos serviços de saúde. No entanto, apesar dos esforços por parte dos profissionais de saúde de interação com sua clientela, aspectos relacionados aos processos socioculturais subjacentes aos modos de vida muitas vezes são ignorados ou desconhecidos (Garnelo e Langdon, 2005). Assim, é preciso conhecer e valorizar essas práticas e entender que a procura de cuidados por esse paciente é variada e complexa.

Outro aspecto observado durante as conversas e identificado como uma das preocupações principais desses pacientes é o período de tempo que irão permanecer longe de casa e sua inquietação quanto aos familiares que ficaram na comunidade. Quando o paciente indígena tem o papel de provedor da casa, questões ligadas ao cuidado e subsistência da família eram relatadas como fontes de preocupação. 0 acompanhante compartilhava as mesmas apreensões, pois também tinha família para cuidar. Em alguns casos relatavam a disponibilidade de permanecer determinado período de tempo, sendo necessário buscar outro acompanhante na comunidade para revezamento. A partir dessas demandas, a equipe do Ambulatório do Índio discutia com a CASAI SP a resolução dessas questões, nem sempre fáceis em virtude das dificuldades burocráticas e em algumas situações a ausência de outra pessoa que pudesse fazer o papel de acompanhante.

Outra proposta desta atividade foi proporcionar aos alunos momentos de aprendizado sobre o atendimento à saúde indígena, produzir reflexões a partir desse acolhimento em serviço de alta complexidade.

O trabalho agregou muito conhecimento principalmente na relação entre equipe médica e paciente, uma vez que foi necessário aprender a transpor as barreiras culturais para estabelecer vínculo de confiança e acolhimento. Acredito que essa experiência foi enriquecedora para a minha formação, pois aprendi que por mais difícil que seja se comunicar e lidar com um paciente é sempre importante ter empatia, ouvi-lo e ter um bom relacionamento, o que é um aprendizado essencialmente prático (MDS, aluna de graduação em medicina) (UNIFESP, 2010, p. 8).

Nos serviços de saúde de média e alta complexidade, é fundamental que as equipes multiprofissionais propiciem ambiente favorável para promoção do cuidado com diálogo envolvendo o paciente e sua família com intuito de identificar necessidades, compartilhar decisões e esclarecer dúvidas quanto ao diagnóstico e tratamento. O relato de caso a seguir, exemplifica uma situação comum. Um pai, ansioso e preocupado, que acompanhava o filho com câncer, hospitalizado e com prognóstico bastante reservado, necessitava acompanhamento mais próximo por parte da equipe do Ambulatório do Índio. Em uma das conversas realizadas, as necessidades percebidas foram: a importância de convocar a mãe, que estava na aldeia, para também acompanhar o filho doente; disponibilizar acesso telefônico para contato com familiares na aldeia e a própria necessidade desse pai de ter com quem conversar. A equipe, entendendo a gravidade do caso, também ofereceu suporte caso fosse necessário convocar pajé da aldeia para participar do projeto terapêutico. Ao final da conversa, esse pai disse: Estou me sentindo muito bem, conversar, dialogar é muito importante. Vocês se preocupam comigo. Estou muito agradecido. Estou me sentindo acolhido aqui (Conversa com L. Xavante em 2012). A equipe do Ambulatório do Índio tem vivenciado e estimulado situações em que o paciente solicita a presença do pajé, principalmente quando 
está hospitalizado e mais vulnerável, pois acredita e valoriza outras práticas de cura que podem ser articuladas com a biomedicina como disposto na "Política Nacional de Atenção à Saúde dos Povos Indígenas” (Brasil, 2002b). Para isso, é necessário negociar junto à equipe hospitalar local reservado para o pajé realizar seus rituais que misturam uso de fumo, ervas, banhos e chás.

O processo saúde-doença na visão do indígena perpassa as noções de doença e tratamento da biomedicina que se esgota nos processos biológicos. A concepção indígena de adoecimento e cura faz parte da ordem cosmológica e envolve forças invisíveis, da natureza e humanas. O significado da doença é construído a partir da procura das causas do sofrimento que vai muito além da nossa perspectiva limitada ao corpo físico. Em algumas situações onde ocorre a quebra de regras, tabus ou conflito social pode provocar o encadeamento do processo de doença e a cura deverá abarcar não somente o sofrimento físico, mas também o espiritual e moral. É essencial que os profissionais de saúde desenvolvam uma competência cultural como parte de sua competência clínica, relativizando a biomedicina, seu conhecimento. É necessário que esses profissionais estejam abertos para ouvir o paciente indígena e como estão percebendo sua experiência de doença na tentativa de construir uma atenção diferenciada (Langdon, 2005).

A identificação de outros atores sociais que compõem o universo sociocultural do paciente é alcançada por meio do diálogo respeitoso que configura condição indispensável para aproximação das concepções e práticas sobre o processo saúde-doença e a sua rede social. As negociações terapêuticas têm como objetivo atingir resultados que combinem maiores chances de eficácia biomédica com aceitabilidade cultural (Brasil, 2007).

A diversidade cultural dos pacientes indígenas, suas dúvidas, inseguranças, medos e preocupações permeiam o processo de cuidar e são questões que devem ser observadas pela equipe multiprofissional de referência. É difícil para o indígena adaptar-se a uma nova rotina, à ociosidade em que ficam submetidos na CASAI, a distância da família e comunidade, convivendo com outra cultura, outros valores. Perceber e intervir nessas questões é essencial para promoção do acolhimento e vínculo.

\section{Projeto de extensão: Promoção e educação em saúde indígena}

A educação em saúde como estratégia facilitadora da promoção da saúde "é um campo de práticas e de conhecimentos que tem se ocupado com a criação de diálogos entre a ação profissional e o pensar e fazer cotidiano da população" (Vasconcelos, 2004, p. 68). Candeias (1997) conceitua a educação em saúde como experiências de aprendizagem que procuram desencadear mudanças de comportamento individual podendo ser desenvolvidos em quatro diferentes ambientes: na escola, no local de trabalho, no ambiente clínico e na comunidade. Para Santos (2008), é importante superar posições simplistas diante do desafio de promover a saúde e qualidade de vida. A razão dialógica e a produção compartilhada de conhecimentos estão voltadas para "promover a saúde com" e "não promover a saúde para".

A partir da identificação de casos de câncer do colo do útero em mulheres indígenas atendidas no Ambulatório do Índio, iniciou-se um projeto de extensão em saúde da mulher. 0 processo de trabalho deu-se com a participação de alunos e da enfermeira do setor que estruturaram um roteiro de entrevista que valorizou aspectos culturais da mulher indígena relacionados à sua ocupação/atividade na aldeia, práticas da medicina indígena como o uso de ervas para tratar problemas de saúde e evitar gravidez, cuidados no período menstrual e gestacional, presença ou não de parteiras na aldeia. Também foi importante a identificação de necessidades, criação de vínculo, a oferta do exame citopatológico com atividade educativa, estimulando o autocuidado. A atividade educativa envolveu a demonstração para as mulheres indígenas, por meio de modelo pélvico, do exame ginecológico e a coleta de material cervicovaginal para prevenção do câncer do colo do útero. 0 trabalho foi estruturado de modo a atender as dimensões assistencial, educativa e científica. Buscou-se proporcionar momentos de aprendizado com troca de experiências, valorizando a relação entre o profissional de saúde e paciente num contexto culturalmente diferenciado.

Os principais aspectos que orientaram o trabalho foram a exposição dessas mulheres aos fatores de risco para o câncer do colo do útero, as dificuldades 
de realização e obtenção de resultados do exame preventivo nas áreas indígenas (Pereira e col., 2011; Pereira, 2011). Soma-se a isso o pouco acesso aos cuidados e prevenção da doença, a oportunidade da coleta do exame e da abordagem educativa, possível de ser realizada com as mulheres que permanecem na CASAI SP como pacientes ou acompanhantes. Também a necessidade dos alunos de se aproximar da saúde da mulher indígena.

Identificamos que grande parte dessas mulheres não havia realizado o exame preventivo do câncer do colo do útero em suas aldeias e pouco conheciam sobre esse exame. Apesar de ser uma prática educativa e de prevenção focal, acreditamos que criar espaços como estes possam contribuir para melhoria da saúde dessa população.

Nesse sentido, foram enfatizadas as experiências e saberes contextualizados dessas mulheres como sujeitos envolvidos em um processo de práticas educativas mediada pelo diálogo e troca. As conversas partiram do conhecimento prévio das mulheres indígenas sobre o que era o câncer do colo do útero. Pudemos perceber, nesse primeiro contato, alguns conhecimentos que traziam sobre essa doença:

É uma doença que vem através da inflamação, forma ferida no colo do útero.

Provoca sangramento e dor.

A doença começa no útero.

Vai apodrecendo por dentro.

Já ouvi falar sobre a verruga genital.

Tem cura quando está no começo e se tiver avançado a pessoa morre.

o que falam é que tem que ir ao médico todo ano.

Tem que fazer exame para não dar câncer, se cuidar.

o câncer do colo uterino é muito perigoso, uma doença ruim, tem que se cuidar.

Na minha aldeia duas mulheres morreram com esta doença, é uma doença horrivel.

Já ouvi falar, mas não sei dizer.

A possibilidade de conhecer e vivenciar na prática outras dimensões do processo saúde-doença, perceber as especificidades culturais foram enriquecedoras para agregar experiências em saúde indígena durante a formação profissional como a necessidade de ter um intérprete em situações em que os indígenas expressam dificuldade na língua portuguesa. O estranhamento dos indígenas aos padrões alimentares e rotinas diferentes daqueles da sua cultura. Além das práticas de cuidado com o corpo como regras e tabus alimentares relacionados ao período menstrual, gravidez, parto e puerpério. Os alunos perceberam a importância de conhecer e demonstrar interesse sobre aspectos da cultura na primeira abordagem ao paciente indígena, podendo facilitar a aproximação e vínculo. Uma das questões culturais abordadas e destacadas pelas alunas relacionava-se aos cuidados da mulher indígena no período menstrual. Foram identificados cuidados que envolviam restrições alimentares como "não chupar cana, não comer alguns tipos de peixe, carne de porco e ovo", e restrições relacionadas às atividades diárias como "não fazer comida, não sair de casa, não carregar peso na cabeça". Além disso, outras questões como "evitar ter cheiro de menstruação e as pessoas perceberem, não ter relação sexual, ficar fechada em um quarto sob os cuidados da mãe tomando ervas e banho da cintura para baixo". Os rituais que permeiam o período menstrual da mulher indígena podem ser observados em diversos povos. Um desses rituais é a reclusão da menina logo após a primeira menstruação, que é uma fase de preparação para a vida adulta, muito comum entre os povos xinguanos. Neste período a menina recebe cuidados da mãe e do pajé fazendo uso de ervas, evitando certos tipos de peixe, mel, pimenta e alimentos gordurosos e abstinência sexual (Rodgers, 2002). Esta abordagem possibilitou refletir sobre a atuação do profissional de saúde nas diferentes realidades socioculturais e a importância de desenvolver competências culturais, facilitadoras na aproximação entre o paciente e o profissional.

O conhecimento de hábitos e costumes relacionados à outra cultura chamou atenção das alunas para a importância de reconhecê-las e valorizá-las na relação intercultural na abordagem ao paciente.

Durante a graduação de medicina são poucas as oportunidades de entrar em contato com outras culturas e modos de ver o paciente e a doença. Acompanhar os pacientes atendidos no Ambulatório do Índio é uma boa oportunidade para ter essa visão diferente, conhecer outros hábitos e tradições contados diretamente pelo paciente e não apenas pela literatura. Além disso, nos primeiros anos da 
graduação, não há contato do aluno com pacientes, dessa forma, o acompanhamento desses pacientes é uma chance de praticar a relação médico-paciente, vista apenas na teoria nesses primeiros anos (C.S.M, aluna do $2^{\circ}$ ano de graduação em medicina) (UNIFESP, 2012, p. 5).

Outro aspecto interessante foi possibilitar que as mulheres indígenas falassem de suas queixas em um ambiente mais acolhedor e feminino. Por ser um assunto que, geralmente, causa constrangimento, essas mulheres podem deixar de referir problemas ginecológicos na consulta médica. Todas as mulheres que apresentaram alguma queixa ou que tiveram alteração no exame citopatológico foram encaminhadas para serviço de ginecologia da UNIFESP.

A proposta de formar vínculo com essas mulheres que ultrapasse o objetivo de resolução de um problema de saúde, mas adentre nas interfaces entre saúde, cultura e modo de vida, num exercício constante de aprendizado com o outro desafiou a equipe multiprofissional. Neste período, acreditamos que foi de grande valia para o aprendizado da equipe e para as próprias mulheres que aceitaram participar desta atividade. Compreendemos que esta abordagem, ainda que inicial e pontual possa ajudar no entendimento das mulheres indígenas na prevenção do câncer do colo do útero, indicar outros aspectos relevantes sobre saúde da mulher indígena e propiciar espaço de discussão entre as mulheres e os profissionais de saúde. Esta primeira abordagem em saúde das mulheres indígenas, de diferentes etnias, atendidas no Ambulatório do Índio em conjunto com alunos de graduação, ainda não foi suficiente para aprofundar o conhecimento sobre o papel feminino nas sociedades indígenas, a organização das famílias, os padrões de casamento, as relações entre homens e mulheres, que são fatores relevantes para abordar a saúde reprodutiva dessas mulheres. Identificamos que são temas relevantes que devem ser explorados no contato com a mulher indígena e que devem ser construídos aos poucos, com sucessivas aproximações, para que seja possível formar vínculo e gerar propostas efetivas de atendimento segundo suas necessidades.

A importância de planejar serviços que vão ao encontro das reais necessidades destas mulheres está ligada a compatibilizar um sistema que seja efetivo em termos dos padrões biomédicos com o atendimento das demandas e necessidades específicas de cada povo, considerando suas particularidades epidemiológicas e culturais, buscando o diálogo interdisciplinar e interétnico (Athias, 2004; Conklin, 2004).

Os serviços de saúde devem atuar como mediadores da promoção da saúde, assumindo a responsabilidade em proporcionar um ambiente favorável para produção do cuidado. A promoção da saúde consiste em proporcionar às pessoas os meios necessários para melhorar sua saúde e exercer um maior controle sobre ela, garantindo o acesso universal à saúde com equidade. Para isso, as estratégias e programas devem adaptar-se às necessidades locais e às possibilidades específicas de cada país e região, e ter em conta os diversos sistemas sociais, culturais e econômicos. Além disso, deve-se incrementar o acesso aos serviços de saúde de grupos considerados menos privilegiados e mais vulneráveis como os povos indígenas, minorias étnicas e imigrantes (OPAS, 1978, 1986, 1988).

\section{Considerações finais}

O Ambulatório do Índio e o Hospital São Paulo da EPM vêm se constituindo ao longo desses anos em espaço permanente de reflexão sobre o atendimento aos povos indígenas de diferentes etnias que vivem múltiplas realidades culturais, linguísticas e de contato com a sociedade brasileira, lançando mão das experiências anteriores da EPM/Projeto Xingu no atendimento a essa população nos campos da assistência, ensino, pesquisa e extensão.

As experiências apreendidas no atendimento ao paciente indígena mostraram quão complexa e delicada é a permanência deste paciente em um ambiente diverso e distante de sua realidade. Este trabalho contribuiu para a reflexão sobre a necessidade de os serviços de saúde de média e alta complexidade olhar para os sujeitos indígenas a partir de suas diferenças e vulnerabilidades, permitindo que o outro se aproxime e que essa aproximação coadune com a formação de vínculo e acolhimento.

A diversidade étnica e cultural dos pacientes indígenas apresentou-se como um campo de conhecimento com muitos desafios e também 
possibilidades no desenvolvimento de projetos de extensão, revelando-se enriquecedor para a vivência e aprendizado dos profissionais de saúde e alunos de graduação. Apesar de o trabalho desenvolvido apresentar abordagens incipientes e pontuais, este se mostrou agregador de aprendizado a futuros profissionais com poucas oportunidades de vivências na saúde indígena.

A equipe multiprofissional no Ambulatório do Índio vem se esforçando em privilegiar uma abordagem que enfatiza a relação intercultural, o acolhimento, a promoção e educação em saúde e a sensibilização a partir das diferenças. É fundamental que os profissionais que trabalham na saúde indígena desenvolvam competências culturais para minimizar conflitos no lidar com o diferente. A necessidade de trazer experiências de um serviço de saúde especializado no atendimento a pacientes indígenas vem ao encontro das novas propostas de organização e estruturação da política de saúde indígena no País. Estimular que outros serviços de saúde disponham de equipes de referência e participação de alunos de graduação no atendimento diferenciado, em especial nos serviços de saúde de média e alta complexidade é um avanço para a saúde indígena no Brasil.

\section{Colaboração dos autores}

Pereira e Biruel contribuíram com a concepção do estudo, elaboração e aprovação da versão final do manuscrito. Souza Oliveira e Rodrigues colaboraram na revisão do manuscrito.

\section{Referências}

ATHIAS, R. Corpo, fertilidade e reprodução entre os Pankararu: perspectivas e alcances. In: MONTEIRO, S.; SANSONE, L. Etnicidade na América Latina: um debate sobre raça, saúde e direitos reprodutivos. Rio de Janeiro: Fiocruz, 2004. p. 189-209.

BARUZZI, R. G. A universidade na atenção à saúde dos povos indígenas: a experiência do Projeto Xingu da Universidade Federal de São Paulo/ Escola Paulista de Medicina. Saúde e Sociedade, São Paulo, v. 16, n. 2, p. 182-186, 2007.
BRASIL. Plano Nacional de Extensão

Universitária: edição atualizada 2000 / 2001. Brasília, DF, 2001.

BRASIL. Ministério da Saúde. Gabinete do Ministro. Portaria $n^{0}$ 254, de 31 de janeiro de 2002. Aprova a Política Nacional de Atenção à Saúde dos Povos Indígenas. Diário Oficial da União, Brasília, DF, 31 jan. 2002a. Seção 1, p. 1. Disponível em: <http:// 189.28.128.10o/dab/docs/legislacao/ portaria254-31_01_02.pdf $>$. Acesso em: 15 fev. 2012. BRASIL. Ministério da Saúde. Política Nacional de Atenção à Saúde dos Povos Indígenas. Brasília, DF, 2002b.

BRASIL. Ministério da Saúde. Secretaria de Atenção à Saúde. Núcleo Técnico da Política Nacional de Humanização. Clínica ampliada, equipe de referência e projeto terapêutico singular. 2. ed. Brasília, DF, 2007.

BRASIL. Ministério da Saúde. Secretaria de Atenção à Saúde. Núcleo Técnico da Política Nacional de Humanização. HumanizaSUS: documento base para gestores e trabalhadores do SUS. 4. ed. Brasília, DF, 2008.

BRASIL. Ministério da Saúde. Secretaria de Atenção à Saúde. Núcleo Técnico da Política Nacional de Humanização. Acolhimento nas práticas de produção de saúde. 2. ed. Brasília, DF, 2010.

BRASIL. Ministério da Saúde. Secretaria de Atenção à Saúde. Departamento de Ações Programáticas e Estratégicas. Atenção hospitalar. Brasília, DF, 2011.

BRASIL. Secretaria Especial de Saúde Indígena SESAI. Brasília, DF, 2012. Disponível em: <http:// portalsaude.saude.gov.br/index.php/o-ministerio/ principal/secretarias/secretaria-sesai>. Acesso em: 23 mar. 2012.

CAMPINHA-BACOTE, J. The quest for cultural competence in nursing care. Nursing Forum, Malden, v. 30, n. 4, p. 19-25, 1995.

CAMPINHA-BACOTE, J. The process of cultural competence in the delivery of healthcare services: a model of care. Journal of Transcultural Nursing, Tuscaloosa, v. 13, n. 3, p. 181-184, 2002. 
CANDEIAS, N. M. F. Conceitos de educação e de promoção em saúde: mudanças individuais e mudanças organizacionais. Revista de Saúde Pública, São Paulo, v. 31, n. 2, p. 209-213, 1997.

CAVALCANTI FILHO, J. B. et al. Acolhimento coletivo: um desafio de novas formas de produzir o cuidado. Interface: Comunicação, Saúde, Educação, Botucatu, v. 13, n. 31, p. 315-328, 2009.

COELHO, M. A.; JORGE, M. S. B. Tecnologia das relações como dispositivo do atendimento humanizado na atenção básica à saúde na perspectiva do acesso, do acolhimento e do vínculo. Ciência \& Saúde Coletiva, Rio de Janeiro, v. 14, n. 1, p. 1523-1531, 2009.

CONKLIN, B. A. O conceito do direito reprodutivo na interseção de saúde, gênero e etnicidade indígena. In: MONTEIRO, S.; SANSONE, L. (Org.). Etnicidade na América Latina: um debate sobre raça, saúde e direitos reprodutivos. Rio de Janeiro: Fiocruz, 2004. p. 175-188.

FREIRE, P. Pedagogia da autonomia: saberes necessários à prática educativa. São Paulo: Paz e Terra, 1996.

GARNELO, L.; LANGDON, J. A antropologia e a reformulação das práticas sanitárias na atenção básica à saúde. In: MINAYO, M. C. S.; COIMBRA, C. (Org.). Críticas e atuantes: ciências sociais e humanas em saúde na América Latina. Rio de Janeiro: Fiocruz, 2005. p. 136-156.

GIMENO, S. G. A. et al. Perfil metabólico e antropométrico de índios Aruák: Mehináku, Waurá e Yawalapití, Alto Xingu, Brasil Central, 2000/2002. Cadernos de Saúde Pública, Rio de Janeiro, v. 23, n. 8, p. 1946-1954, 2007.

HENNINGTON, E. A. Acolhimento como prática interdisciplinar num programa de extensão universitária. Cadernos de Saúde Pública, Rio de Janeiro, v. 21, n. 1, p. 256-265, 2005.

ISA - INSTITUTO SOCIOAMBIENTAL. Povos indígenas no Brasil: população indígena no Brasil. São Paulo, 2012. Disponível em: <http:// pib.socioambiental.org/pt/c/o/1/2/populacaoindigena-no-brasil>. Acesso em: 2 abr. 2012.
LANGDON, E. J. A construção sociocultural da doença e seu desafio para a prática médica. In: BARUZZI, R. G.; JUNQUEIRA, C. (Org.). Parque Indígena do Xingu: saúde, cultura e história. São Paulo: Terra Virgem, 2005. p. 115-133.

MENDONÇA, S. B. M. Saúde indígena: distâncias que aproximam. In: BRASIL. Ministério da Saúde. Secretaria de Atenção à Saúde. Política Nacional de Humanização. Brasília, DF, 2010. p. 185-188.

MENÉNDEZ, E. Modelos de atención de los padecimientos: de exclusiones teóricas y articulaciones prácticas. Ciência \& Saúde Coletiva, Rio de Janeiro, v. 8, n. 1, p. 185-208, 2003.

\section{OPAS - ORGANIZAÇÃO PAN-AMERICANA DA} SAÚDE. Declaração de Alma Ata. Alma-Ata, 1978. Disponível em: <http://www.legislacion.bvsalud. org/php/level.php?lang=pt\&component=37\&it em=6>. Acesso em: 5 fev. 2012.

\section{OPAS - ORGANIZAÇÃO PAN-AMERICANA DA} SAÚDE. Carta de Ottawa. Ottawa, 1986. Disponível em: <http://bvsms.saude.gov.br/bvs/publicacoes/ carta_ottawa.pdf $>$. Acesso em: 15 jan. 2012.

OPAS - ORGANIZAÇÃO PAN-AMERICANA DA SAÚDE. Declaração de Adelaide. Adelaide, 1988. Disponível em: <http://www.saudepublica.web. pt/o5-promocaosaude/Dec_Adelaide.htm>. Acesso em: 22 jan. 2012.

PEREIRA, E. R. et al. Prevenção do câncer do colo do útero: buscando estratégias para o seu enfrentamento. In:____. Curso de especialização em saúde indígena. São Paulo: Unifesp, 2011. p. 1-3. PEREIRA, E. R. Prevenção do câncer do colo do útero em população feminina do Parque Indígena do Xingu, Mato Grosso. 2011. Tese (Doutorado em Ciências) - Universidade Federal de São Paulo, São Paulo, 2011.

RODGERS, D. A soma anômala: a questão do suplemento no xamanismo e menstruação Ikpeng. Mana, Rio de Janeiro, v. 8, n. 2, p. 91-125, 2002. Disponível em: <http://www.scielo.br/pdf/mana/ v8n2/16138.pdf>. Acesso em: 19 maio 2014.

SANTOS, B. S. A gramática do tempo: para uma nova cultura política. 2. ed. São Paulo: Cortez, 2008. 
SANTOS, V. S.; COIMBRA JR, C. E. A. Cenários e tendências da saúde e da epidemiologia dos povos indígenas no Brasil. In: COIMBRA JR, C. E. A. et al. (Org.). Epidemiologia dos povos indígenas no Brasil. Rio de Janeiro: Fiocruz: Abrasco, 2003. p. 13-47.

SALVO, V. L. M. A. et al. Perfil metabólico e antropométrico dos Suyá: Parque Indígena do Xingu, Brasil Central. Revista Brasileira de Epidemiologia, São Paulo, v. 12, n. 3, p. 458-468, 2009.

SILVEIRA, N. H. O conceito de atenção diferenciada e sua aplicação entre os Yanomami. In: LANGDON, E. J. et al. (Org.). Saúde dos povos indígenas: reflexões sobre antropologia participativa. Rio de Janeiro: Contra Capa: Associação Brasileira de Antropologia, 2004. p. 111-127.
VASCONCELOS, E. M. Educação popular: de uma prática alternativa a uma estratégia de gestão participativa das políticas de saúde. Physis:

Revista de Saúde Coletiva, Rio de Janeiro, v. 14, n. 1, p. 67-83, 2004 .

UNIFESP - UNIVERSIDADE FEDERAL DE SÃO PAULO. Ambulatório do Índio/Projeto Xingu. Relatório de atividade do Ambulatório do Índio. São Paulo, 2008.

UNIFESP - UNIVERSIDADE FEDERAL DE SÃO PAULO. Ambulatório do Índio/Projeto Xingu. Relatório de atividade: Projeto de Extensão em Acolhimento. São Paulo, 2010.

UNIFESP - UNIVERSIDADE FEDERAL DE SÃO PAULO. Ambulatório do Índio/Projeto Xingu. Relatório de atividade: Projeto de Extensão em Saúde da Mulher Indígena. São Paulo, 2012. 